\title{
Manhole Cover Displacement Caused by the Release of Entrapped Air Pockets
}

\author{
Jue Wang and José G. Vasconcelos
}

Auburn University, Auburn, Alabama.

\begin{abstract}
Stormwater systems undergoing rapid filling may present a variety of operational problems, one such being the displacement of manhole covers, which can threaten both traffic and pedestrians. There are scarce documentation and few measurements of flow conditions in rapidly filling stormwater systems, and it is speculated that air pressurization within manholes leads to such displacements. There can be different causes of air pressurization in manholes, among which is the release of entrapped air pockets through water-filled shafts. Research has indicated that such releases will result in the displacement of the free surface within these manholes, which in turn may create conditions for air to develop enough pressure to overcome the weight of a manhole cover and displace it. This paper presents results from an ongoing computational fluid dynamics (CFD) simulation of air pocket release in shafts with limited ventilation at the cover. Results indicate that releases of large air pockets can create pressure surges that far exceed the threshold for manhole cover displacement, and that pressure rise can occur within a few seconds following air admission into the shaft. The ultimate goal of this investigation is to provide better guidance for the management of air in junctions within stormwater systems, and to prevent operational issues that are linked to air-water flows.
\end{abstract}

\section{Introduction}

Manholes and shafts are integral components of stormwater infrastructure in urban areas, and allow for inspection of the system and inflows into sewers and tunnels. Manhole covers prevent people, animals, and objects from falling into the subterranean conduits. However, manhole cover displacement is a possible accident hazard to the public, particularly for pedestrian and vehicular traffic (Metcalfe 2012; Fourie 2015; Crimaldi and Ramos 2016). Manhole cover displacement can have various causes, including rapid filling of sewers and pressure surges within manholes, among other mechanisms. This work focuses on air-water pressure surges in manholes under rapid filling conditions.

Rapid filling of stormwater or sewer systems can lead to air entrapment, as described by Li and McCorquodale (1999) and Vasconcelos and Wright (2006). Once air is entrapped in large pockets, it moves within the conduits and may be released in an uncontrolled fashion through a ventilation point. In addition to the mechanisms of air entrapment and motion, transient flows can cause detrimental pressure surges due to air compressibility (Vasconcelos and Leite 2012).

Regarding air-water surging, Martin's (1976) pioneering work developed an analytical solution based on a rigid column model that describes the pressure surge caused by the rapid filling of a pipeline with a large air pocket. Zhou (2000) and Zhou et al. (2002a; 2002b) observed that three types of pressure oscillation patterns can be generated depending on the size of the orifice that allows air to be released:

1. Limited air ventilation condition: long-period pressure surges dominate the compression-expansion processes, with peak pressure magnitudes from one to three times the initial driving pressure attributed to air cushion effects;

2. Adequate air ventilation condition: air cushion effects are not significant; water inflow easily displaces air and upon reaching the air ventilation location it slams against the location and generates water hammer pressures, which could be up to 15 times the peak pressure magnitude of the initial driving pressure; and

3. Intermediate air ventilation condition: a condition intermediate between the two preceding cases; a long-period pressure surge dominates until sufficient air is released, at which point slamming occurs, triggering water hammer pressures.

Zhou et al. (2004) experimentally studied and numerically modeled the situation of an air pocket located at a vertical pipe end, showing similar findings. Zhou et al. (2011) created computational fluid dynamics (CFD) simulations with both 2D and $3 \mathrm{D}$ volume of fluid (VOF) methods, showing that 2D and 3D CFD models can better describe the flow physics and pressure oscillations than a 1D elastic water model. Zhou et al. (2013) observed that the pressure surge magnitude could be much higher

Wang, Jue, and José G. Vasconcelos. 2018. Manhole Cover Displacement Caused by the Release of Entrapped Air

Pockets. Journal of Water Management Modeling 26:C444. https://doi.org/10.14796/JWMM.C444

(c) CHI 2018. www.chijournal.org ISSN 2292-6062. 
when two air pockets exist in the pipeline rather than only one air pocket. One essential limitation of the above research is that the potential air pressurization caused by the release of air pockets through vertical shafts is still poorly understood.

When an air pocket moves along sewers and tunnels, it may be released if it arrives at a manhole or ventilation shaft. If the ventilation shaft is filled with water, the air pocket can displace water in the vertical structure as it moves upward. Laboratory and numerical investigations (Vasconcelos and Wright 2011; Lewis 2011; Muller et al. 2017) have shown that the vertical motion of air pockets in these shafts can lead to significant water column displacement and potentially result in a geyser. While relevant, these past research efforts have not focused on the possibility of air compression as the entrapped pocket moves upward and displaces air at the top of the vertical structures. This is relevant since in various circumstances there is limited ventilation available for air in manholes and shafts, leading to the possibility of a pressure build-up and consequent manhole cover displacement. This knowledge gap is the focus of this work.

\section{Objectives}

This research presents an implementation of a CFD model that was developed to study the air pressurization caused by uncontrolled air pockets that are released through water-filled manholes. The CFD model follows the work of Muller et al. (2017), and considers various vent configurations for manhole covers. Initially the CFD model was validated for air-water surging processes using the experimental data of Zhou et al. (2011). After this step, we systematically investigated the air pressurization characteristics when air pockets were released through water-filled manholes, with vents of various dimensions in the manhole covers.

\section{Methodology}

Zhou et al. (2011) published a CFD study that used a VOF method for air pressurization caused by air-water interaction under rapid filling conditions. They showed that both 2D models and 3D models can accurately predict the flow, as well as the pressure surge magnitude and period, in comparison to 1D models. Similarly, we conducted a series of 3D, VOF-based CFD simulations focusing on air pressurization caused by the release of a large air pocket through a water-filled manhole, which involved surging. Our approach follows the simulation results given in the work of Muller et al. (2017), which involved the release of large air pockets. In our model key differences from Muller et al. are the limitation of ventilation orifice size at the top of the vertical shaft and the model scale.

The CFD simulation used the open source CFD library OpenFOAM (OpenFOAM Foundation 2016). VOF method-based (Hirt and Nichols 1981) compressible two-phase Navier-Stokes equations can be expressed as (Svenungsson 2016):

$$
\frac{\partial \rho}{\partial t}+\nabla \cdot(\rho \bar{U})=0
$$

$$
\begin{aligned}
& \frac{\partial(\rho \bar{U})}{\partial t}+\nabla \cdot(\rho \bar{U} \bar{U})=-\nabla p+\nabla \cdot(\mu \nabla \bar{U})+S_{\bar{U}} \\
& \frac{\partial\left(\rho C_{p} T\right)}{\partial t}+\nabla \cdot\left(\rho \bar{U} C_{p} T\right)=\nabla \cdot(k \nabla T)+S_{T} \\
& \frac{\partial \alpha}{\partial t}+\nabla \cdot(\alpha \bar{U})+\nabla \cdot\left((1-\alpha) \alpha U_{r}\right)=0
\end{aligned}
$$

where:

$\rho=$ average density of the fluid within a cell $\left[\mathrm{M} / \mathrm{L}^{3}\right]$,

$\bar{U}=$ flow velocity vector $[\mathrm{L} / \mathrm{T}]$,

$\mu=$ dynamic viscosity $[\mathrm{M} /(\mathrm{LT})]$,

$g=$ gravity acceleration $\left[\mathrm{L} / \mathrm{T}^{2}\right]$,

$p=$ pressure $\left[\mathrm{M} /\left(\mathrm{LT}^{2}\right)\right]$,

$S_{\bar{U}}=$ momentum source term $\left[\mathrm{M} /\left(\mathrm{L}^{2} \mathrm{~T}^{2}\right)\right]$,

$C_{p}=$ specific heat $\left[\mathrm{L}^{2} /\left(\mathrm{T}^{2} \Theta\right)\right]$,

$T=$ temperature $[\Theta]$,

$k=$ thermal conductivity $\left[\mathrm{ML} /\left(\mathrm{T}^{3} \Theta\right)\right]$,

$S_{T}=$ energy source term $\left[\mathrm{M} /\left(\mathrm{LT}^{3}\right)\right]$,

$a=$ fraction of water in the cell (between 1 and 0 ) [1], and

$U_{r}=$ velocity field suitable to compress the interface $[\mathrm{L} / \mathrm{T}]$.

The average density is defined as:

$\rho=\alpha \rho_{w}+(1-\alpha) \rho_{a}$

where:

$\rho_{w}=$ density of water, and

$\rho_{a}=$ density of air.

Equations 1 through 3 represent mass, momentum and energy conservation respectively. Equation 4 is related to the compression effects at the interface. A standard $k-\varepsilon$ model (Launder and Spalding 1974) was used to resolve the turbulence (for brevity, the details of turbulence modeling are not presented here).

The mesh was generated with a polyhedral mesh generator, snappyHexMesh (OpenFOAM Foundation 2016), by morphing an existing mesh to fit the object surface. The simulated model geometry is the same as that of the hypothetical large-scale model from Muller et al. (2017) except for the ventilation orifice sizes at the top of the vertical shaft; the mesh resolutions and independence study are not presented in detail here.

The current CFD model accurately represents the flow characteristics of a large air pocket releasing though a vertical shaft, so we used the model to simulate air-water surging. The experimental data given by Zhou et al. (2011) was used to model air-water surging. The experimental conditions were a $7 \mathrm{~m}$ initial upstream water pressure head and empty pipe at the downstream end of the horizontal pipe apparatus (Figure 1). The pressure was monitored near the pipe end in the manner described by Zhou et al. (2011). The CFD model addressed the model setup in Figure 1 but without the presence of a ball valve, which means in the experiment the opening duration of the ball valve ranges from $0.05 \mathrm{~s}$ to $0.1 \mathrm{~s}$ while in the CFD model it is instantaneous. 
After model validation, a series of simulations with various sizes of ventilation shaft manhole covers were run. The model and the development of the released air pocket are shown in Figure 2. The model consists of a $1 \mathrm{~m}$ diameter $72.74 \mathrm{~m}$ long horizontal tunnel with a large reservoir, open to the atmosphere, connected at the downstream end of the system to sustain pressure. Between the cap (acting as an upstream wall) and the reservoir there is a ventilation shaft positioned $30 \mathrm{~m}$ upstream of the reservoir, with $0.5 \mathrm{~m}$ diameter and $100 \mathrm{~m}$ high. Manhole covers with various vent sizes are at the top of the shaft and are open to the atmosphere.

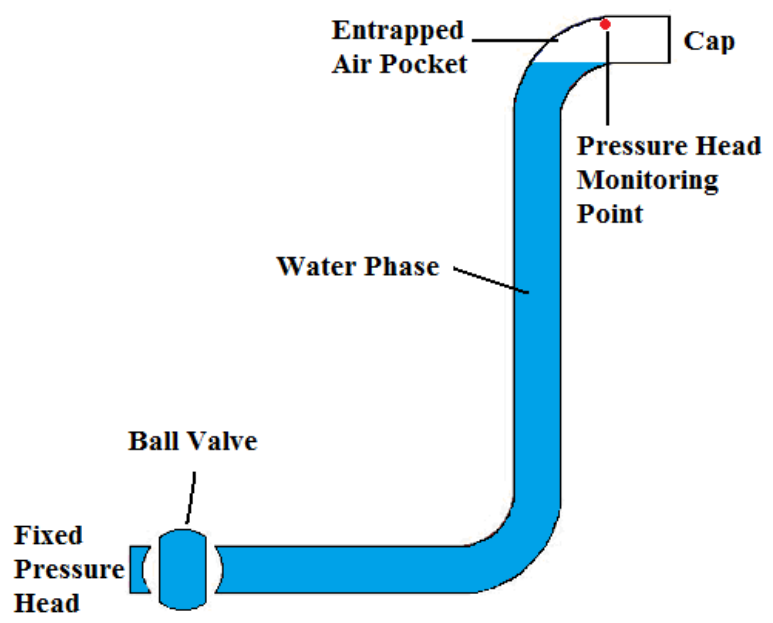

Figure 1 Experimental model sketch from Zhou et al. (2011) and boundary condition setups.

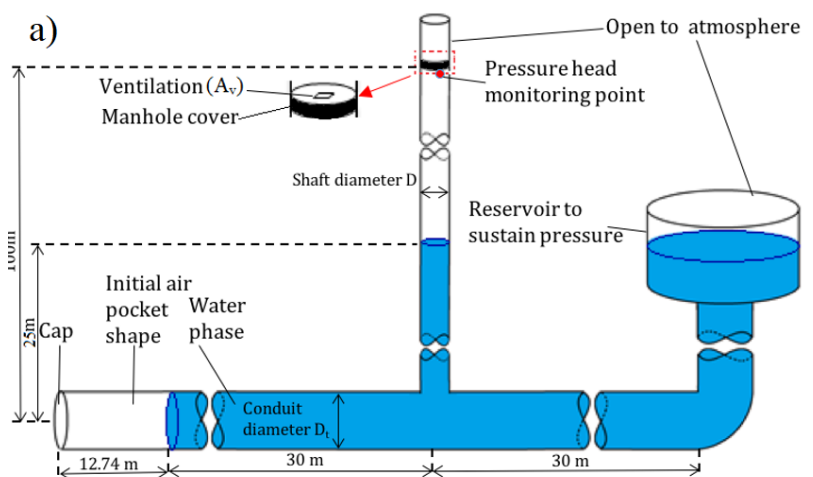

b)

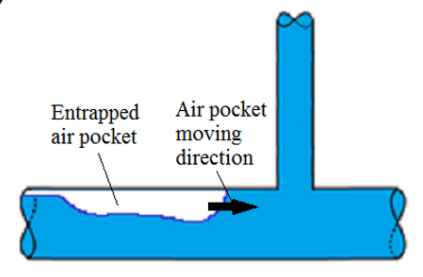

c)

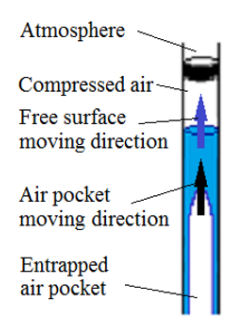

Figure 2 Sketch of the tunnel geometry and development of released air pocket represented by the CFD model: (a) model setup and initial condition; (b) air pocket approaching the manhole; and (c) air pocket moving upwards and air compressed by the rising free surface.
For all tests, the volume of the released air pocket was $10 \mathrm{~m}^{3}$, corresponding to an initial horizontal tunnel length of $12.74 \mathrm{~m}$. The initial water level in the vertical shaft, and hence the hydrostatic pressure head, was $25 \mathrm{~m}$ measured from the horizontal pipe centerline. In order to represent the actual vent of manhole covers, the total vent area $\left(A_{v}\right)$ of a manhole cover is normalized by the manhole cover area $\left(A=0.25 \pi D^{2}\right)$, which is $A_{v}^{*}=A_{v} / A$. Though manhole cover vents are usually customized, most typical vent areas are in the range between $A_{v}^{*}=0.002$ and $A_{v}^{*}=0.02$ (Schladweiler 2018). To simplify the model and to reduce mesh resolution, the manhole cover vent of the current CFD model was set to be a single square hole (as shown in Figure 2a) with areas $\left(A_{v}\right)$ equal to $1 \%, 2 \%, 5 \%$ or $10 \%$ of the shaft cross section area, located at the center of the manhole cover. Considering also the two extreme cases of a shaft that is fully sealed $\left(A_{v}^{*}=0\right)$ or fully opened $\left(A_{v}^{*}=1\right)$, six cases were simulated. All walls in the system were assumed to be smooth concrete. The initial temperature in the system was set to $27^{\circ} \mathrm{C}$.

\section{Results and Discussion}

\subsection{Model Validation}

For the validation stage, as described by Zhou et al. (2011), the high-pressure water advances in the pipe when the upstream valve is opened, leading to compression of the air pocket at the end of the system. As the air is compressed, its pressure exceeds the upstream reservoir pressure, leading to a deceleration of the column and eventual reversal of the water motion back toward the supply reservoir. The pressure head of the air pocket will oscillate as it undergoes such compression and expansion. Figure 3 shows a comparison of the CFD simulated air pressure head with the experimental data. There is good agreement, with just minor differences of pressure head and oscillation frequency.

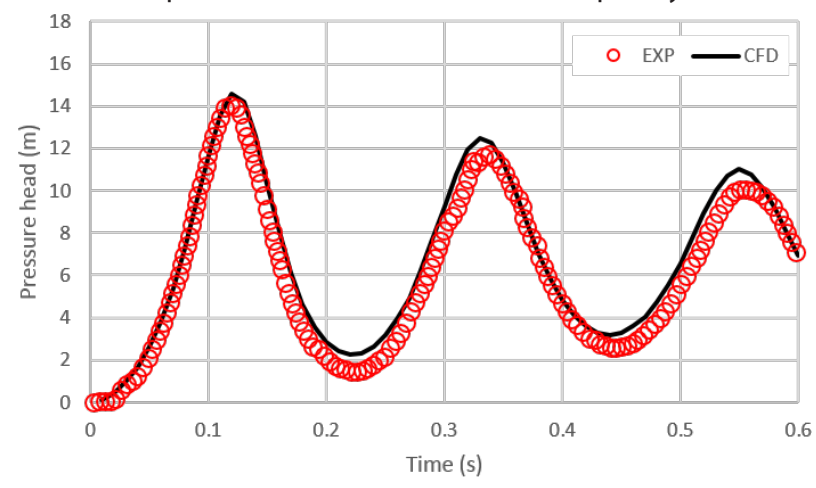

Figure 3 Comparison of air pressurization between 3D CFD simulation from the present work and experiments from Zhou et al. (2011).

\subsection{Simulation of Air Pressurization Created by Air Pocket Releases in Water-Filled Shafts}

The model was well able to describe surging, so we examined the air pressurization characteristics caused by the release of a large 
air pocket through the limited ventilation manhole. The pressure head at the bottom of the manhole cover was monitored by a gauge, as were the corresponding displacement and velocity of the free water surface within the manhole. Time 0 represents the instant when the air pocket was released in the simulation. The free surface displacement and velocity were tracked until the air pocket-water interface broke through the water column surface within the manhole.

The simulation results show that, under conditions of limited ventilation, the air in the manhole can be significantly compressed by the water displacement caused by the rise of the entrapped air pocket, reaching a maximum pressure head close to $10 \mathrm{~m}$ for the case when $A_{v}^{*}=0$. For the largest non-extreme value of $A_{v}^{*}$ that we considered $\left(A_{v}^{*}=0.1\right)$, the peak pressure head was $1.0 \mathrm{~m}$. The results show that in general air pocket releases can cause a large air pressure under a manhole cover. For comparison, the peak air phase pressure heads reported by Klaver et al. (2016) were $<1.7 \mathrm{~m}$ for cases when manholes were subjected to inertial oscillations during rapid filling conditions and for a ventilation area of $A_{v}^{*}=0.0017$.

After air pressure peaked, there was a process of depressurization due to ventilation in all cases except for the case when $A_{v}^{*}=0$. This depressurization may take several seconds to occur, which indicates that air pressure forces acting on the cover may have a significant duration. We also observed that peak pressures occurred sooner with larger $A_{v}^{*}$ values.

Manhole cover sizes and weights vary greatly; some heavy duty manhole covers have weights of $\sim 114 \mathrm{~kg}$. If a (hypothetical) manhole cover has area $0.50 \mathrm{~m}^{2}$ (corresponding to a diameter of $80 \mathrm{~cm}$ ), it would take an air pressure of $2236 \mathrm{~Pa}$ (pressure head $0.23 \mathrm{~m}$ ) to overcome the weight of the manhole. Such values of air pressure can be obtained by the release of an entrapped air pocket at the bottom of a water-filled shaft, as indicated in Figures 4 and 5 .

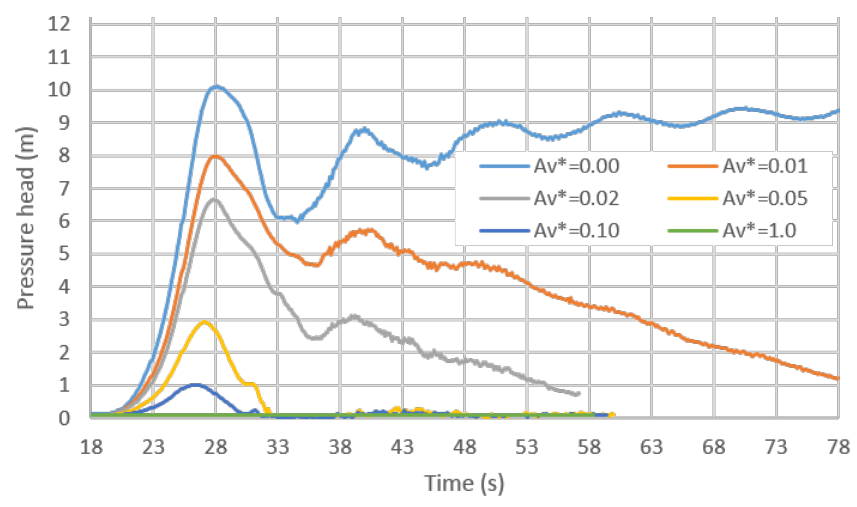

Figure 4 Development of pressurization of the air phase under a manhole cover created by a rising air pocket in a water-filled manhole shaft.

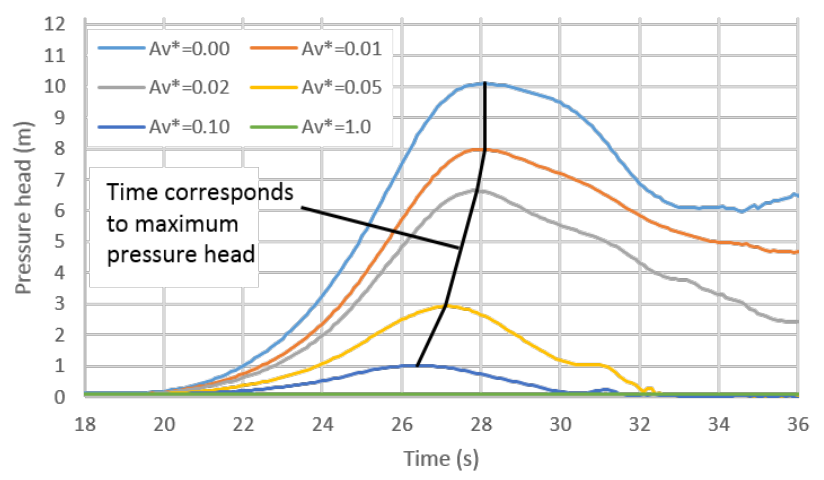

Figure 5 Detail of air pressure variation under a manhole cover for various $A_{v}^{*}$ values.

Clearly, if the manhole cover is bolted to the shaft, the bolts will maintain the cover in position and so transfer the air pressure forces to the supporting ring. As would be expected, structural damage can occur if these forces are excessive, as was reported by Klaver et al. (2016). Assuming that the air pressure under a poorly ventilated manhole cover with an area of $0.5 \mathrm{~m}^{2}$ reached the same range that was obtained in these simulations, the air pressure force could reach $48.7 \mathrm{kN}$.

Note that the maximum air pressure occurred before the breakthrough of the rising air pocket at the top of the water column. As is shown in Figure 6, with higher pressure levels the trajectory of the displaced water column is altered, which suggests that an air cushioning effect reduces the magnitude of the water displacement. When $A_{v}^{*}=1$ the free surface displacement is $\sim 70 \mathrm{~m}$, but for the case of $A_{v}^{*}=0$ this displacement was only $30 \mathrm{~m}$. There was a gradual variation in this displacement among all tested values of $A_{v}^{*}$.

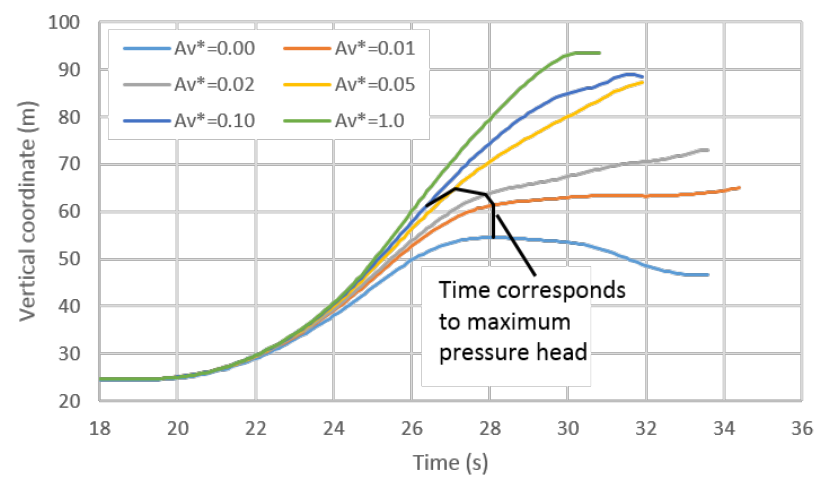

Figure 6 Displacement of the water-free surface in the shaft created by the rising air pocket.

It would also be expected that the air cushioning effect would affect the velocity of the free surface of the water as it moved toward the manhole cover. The peak velocity simulated for the conditions where $A_{v}^{*}=0$ and $A_{v}^{*}=1$ were $6.0 \mathrm{~m} / \mathrm{s}$ and $10.9 \mathrm{~m} / \mathrm{s}$ respectively. In general, the velocity values grew for $\sim 7 \mathrm{~s}$ to $8 \mathrm{~s}$ during the initial air pocket rise and decreased abruptly, as 
shown in Figure 7. Peak velocity times did not coincide with the time where pressure peaked.

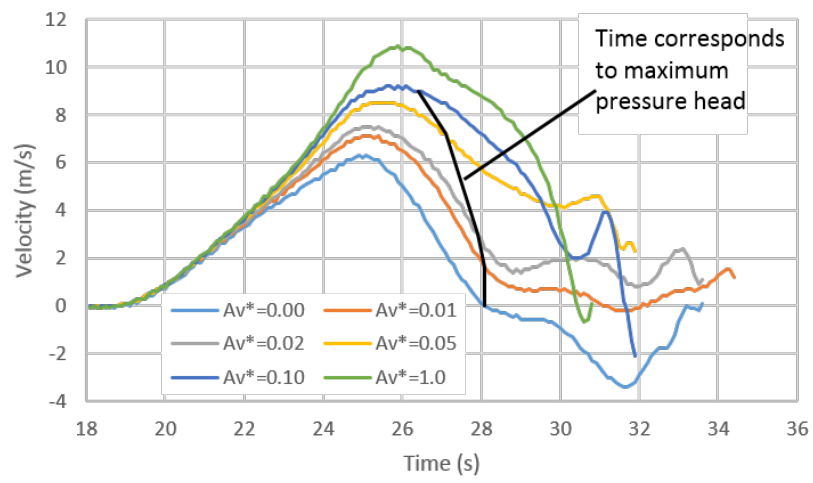

Figure 7 Change in the free-water surface velocity within the manhole for various $A_{v}^{*}$ values.

After the air pocket breaks through the free-water surface within the manhole, a complex air-water bubbly mix remains in the vertical shaft for a significant time. These small air bubbles rise in the column more slowly, with varying velocities that scale with the bubble diameter (Batchelor 1967) and that depend on the water velocity within the column. Such conditions, while they will also lead to air release underneath the manhole cover, were not examined in this study. An illustration of the configuration of the air-water mix in the tower for selected ventilation conditions is shown in Figure 8.

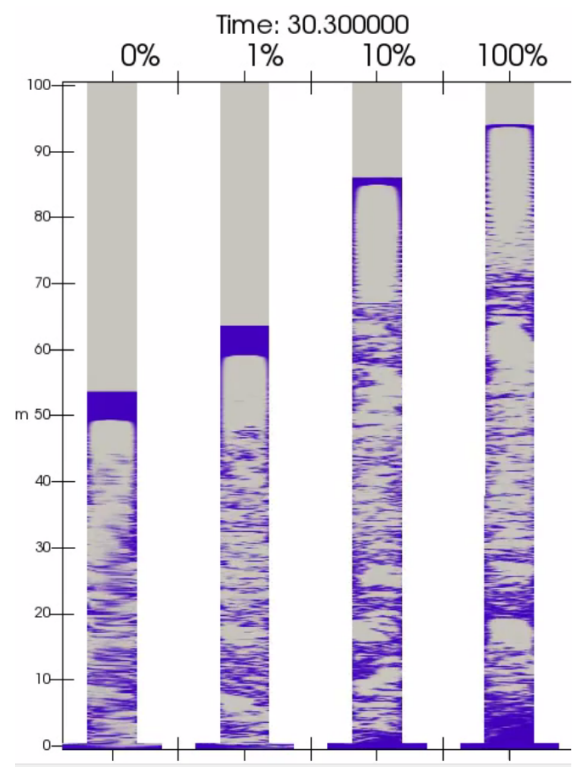

Figure 8 Modeled air-water mixture in ventilation shafts for selected ventilation conditions, at $T=30.3 \mathrm{~s}$.

\section{Conclusions and Future Work}

This work describes an investigation, using CFD, into the characteristics of air pressurization under manhole covers caused by uncontrolled air pocket release in water-filled shafts. The key contribution of our research to an increased understanding of the behaviour of air pockets is to determine to what extent such air pocket releases would affect the forces under manhole covers with varying degrees of ventilation. Although this research is still in its initial stages, there are some relevant findings thus far:

1. The simulation results show that with a limited ventilation manhole cover, the air in the manhole can be highly compressed by the rise of water during air pocket release. The peak pressure values are sufficient to dislodge the manhole cover under the simulated conditions.

2. As would be expected, the magnitude of the compressed air pressure is closely related to the vent size. Highest pressures were observed for cases when the ratio of vent area to the vertical shaft area, $A_{v}^{*}$, was $\leq 0.02$, which is in the range of most typical vent areas in manhole covers. Among the simulated cases, the highest pressures were observed when the shaft was not vented, with a peak pressure head of $9.9 \mathrm{~m}$.

3. While the results of this work are still preliminary, it appears that even with larger ventilation ratio values $\left(0.05 \leq A_{v}^{*} \leq 0.10\right)$ and smaller peak pressure heads ( $1.0 \mathrm{~m}$ to $2.7 \mathrm{~m}$ ) there would be enough force to dislodge for a brief period most manhole covers (i.e. those weighing $\leq 114 \mathrm{~kg}$ ).

4. Both the water rise caused by the air pocket release and its corresponding velocity decreased with a smaller ventilation ratio, suggesting that the lack of ventilation creates a cushion effect against the displacement of the water in the vertical shaft.

Many questions still need further attention. One limitation of this work was the consideration of air pocket release through an intermediate shaft, which may not be representative of all shaft geometries. Other limitations included the use of a single value for parameters such as initial water depth, shaft length and plan area. The effect of the release of air pockets of varying volumes was not studied, nor was the possibility of the ventilation area variation with pressurization, which is the case when manhole covers are displaced by air pressure. It is hoped that future modeling and experimental investigation will address these possibilities.

\section{References}

Batchelor, G. K. 1967. Introduction to Fluid Dynamics. Cambridge: Cambridge University Press.

Crimaldi, L. and N. Ramos. 2016. "Answers Sought in Manhole Cover Fatality on Expressway." Boston Globe, 2016-02-12. https://www.bostonglobe.com/2016/02/12/woman-struckflying-manhole-cover-inside-neill-tunnel-suffers-fatal-injuries/Okpvg6Jx6VF86xsYrA2ZRN/story.html 
Fourie, C. 2015. "Dislodged Manhole Cover Causes Accident." Krugersdorp News, 2015-06-13.

https://krugersdorpnews.co.za/266173/dislodged-manhole-cover-causes-accident/

Hirt, C. and B. D. Nichols. 1981. “Volume of Fluid (VOF) Method for the Dynamics of Free Boundaries." Journal of Computational Physics 39 (1): 201-25.

Klaver, P., D. Collins, K. Robinson and S. Bell. 2016. "Modeling of Transient Pneumatic Events in a Combined Sewer Overflow Storage Tunnel System." Journal of Water Management Modeling 25:C409. https://doi.og/10.14796/JWMM.C409

Launder, B. E. and D. B. Spalding. 1974. “The Numerical Computation of Turbulent Flows." Computer Methods in Applied Mechanics and Engineering 3 (2): 269-89.

Lewis, J. 2011. A Physical Investigation of Air-Water Interactions Leading to Geyser Events in Rapid Filling Pipelines. Ann Arbor, MI: University of Michigan. PhD dissertation.

Li, J. and A. McCorquodale. 1999. "Modeling Mixed Flow in Storm Sewers." Journal of Hydraulic Engineering 125 (11): 1170-80.

Martin, C. S. 1976. “Entrapped Air in Pipelines." In Proceedings, 2nd International Conference on Pressure Surges, vol. 2, 15-27. Bedford, UK: British Hydromechanics Research Association.

Metcalfe, J. 2012. "The Hidden Dangers of Driving Over Manholes: Watch Cars Get Launched into the Air Like Rockets due to III-Fitting Manhole Covers." CityLab, 2012-07-25. https://www.citylab.com/transportation/2012/07/hidden-dangers-driving-over-manholes/2713/.

Muller, K., J. Wang and J. G. Vasconcelos. 2017. "Water Displacement in Shafts and Geysering Created by Uncontrolled Air Pocket Releases." Journal of Hydraulic Engineering 143 (10): 04017043. https://doi.org/10.1061/(ASCE)HY.1943-7900.0001362

OpenFOAM Foundation. 2016. OpenFOAM v4 User Guide. Reading, UK: CFD Direct. https://cfd.direct/openfoam/user-guide-v4/

Schladweiler, J. 2018. The History of Sanitary Sewers. https://www.sewerhistory.org/.

Svenungsson, J. 2016. Solving Electric Field Using Maxwell's Equations and CompressiblelnterFoam Solver. Göteborg: Chalmers University of Technology.

http://www.tfd.chalmers.se/ hani/kurser/OS_CFD_2015/ JosefineSvenungsson/finalJosefine.pdf
Vasconcelos, J. G. and G. M. Leite. 2012. "Pressure Surges Following Sudden Air Pocket Entrapment in Storm-Water Tunnels." Journal of Hydraulic Engineering 138 (12): 1081-9.

Vasconcelos, J. G. and S. J. Wright. 2006. "Mechanisms for Air Pocket Entrapment in Stormwater Storage Tunnels." In World Environmental and Water Resource Congress 2006: Examining the Confluence of Environmental and Water Concerns, edited by R. Graham. Reston, VA: American Society of Civil Engineers.

Vasconcelos, J. G. and S. J. Wright. 2011. "Geysering Generated by Large Air Pockets Released Through Water-Filled Ventilation Shafts." Journal of Hydraulic Engineering 137 (5): 543-55.

Zhou, F. 2000. Effects of Trapped Air on Flow Transients in Rapidly Filling Sewers. Edmonton, Alberta: University of Alberta. $\mathrm{PhD}$ dissertation.

Zhou, F., F. E. Hicks and P. M. Steffler. 2002a. "Transient Flow in a Rapidly Filling Horizontal Pipe Containing Trapped Air." Journal of Hydraulic Engineering 128 (6): 625-34. https://doi.org/10.1061/(ASCE)0733-9429(2002)128:6(625)

Zhou, F., F. E. Hicks and P. M. Steffler. 2002b. “Observations of Air-Water Interaction in a Rapidly Filling Horizontal Pipe." Journal of Hydraulic Engineering 128 (6): 635-9. https://doi.org/10.1061/(ASCE)0733-9429(2002)128:6(635)

Zhou, F., F. E. Hicks and P. M. Steffler. 2004. "Analysis of Effects of Air Pocket on Hydraulic Failure of Urban Drainage Infrastructure." Canadian Journal of Civil Engineering 31 (1): 86-94.

Zhou, L., D.-Y. Liu and B. Karney. 2013. “Investigation of Hydraulic Transients of Two Entrapped Air Pockets in a Water Pipeline." Journal of Hydraulic Engineering 139 (9): 949-59.

Zhou, L., D.-Y. Liu and C.-Q. Ou. 2011. “Simulation of Flow Transients in a Water Filling Pipe Containing Entrapped Air Pocket with VOF Model." Engineering Applications of Computational Fluid Mechanics 5 (1): 127-40. https://doi.org/10.1080/19942060.2011.11015357 